\title{
Crystal structure analysis of $\left[\mathrm{Ca}\left(\mathrm{O}_{3} \mathrm{SC}_{18} \mathrm{H}_{37}\right)_{2}(\mathrm{DMSO})_{2}\right]$, a lamellar coordination polymer and its relevance for model studies in biomineralization
}

\author{
Dirk Volkmer, * Norbert Mayr and Marc Fricke
}

\begin{abstract}
Single crystals of a one-dimensional Ca coordination polymer of the surfactant octadecyl sulfonate $\left(\mathrm{C}_{18} \mathrm{H}_{37} \mathrm{SO}_{3}^{-}\right)$have been grown from hot DMSO solution. The X-ray structure analysis of the compound $\left[\mathrm{Ca}\left(\mathrm{O}_{3} \mathrm{SC}_{18} \mathrm{H}_{37}\right)_{2}(\mathrm{DMSO})_{2}\right](\mathbf{1})$ shows a lamellar interdigitated arrangement of hydrophobic tails of the amphiphilic ligands. Each $\mathrm{Ca}$ ion is coordinated by four different sulfonate groups, and its nearly octahedral coordination environment is completed by two dimethyl sulfoxide (DMSO) ligands. The octadecyl sulfonate ligand coordinates to $\mathrm{Ca}$ ions in a $\mu_{2}$-bridging mode, which contrasts to information from literature suggesting a $\mu_{3}$-bridging coordination mode. Since the growth of highly oriented calcite single crystals underneath Langmuir monolayers of this particular surfactant is often regarded as textbook example of a heteroepitaxy ("template") mechanism in biomineralization, we present a critical discussion of the crystal structure of the title compound in this context.
\end{abstract}

\section{Introduction}

Crystallization of inorganic solids on self-organized surfaces is regarded as an important step in biomineralization and crystal engineering. ${ }^{1,2}$ The putative mechanisms by which an organic substrate might lead to selection of a particular crystal polymorph and/or a specific crystal face of the overgrowing mineral are subject of continued controversial discussions. ${ }^{3}$

In seminal investigations, employing Langmuir monolayers as models of the organic matrix of calcifying organisms, Heywood and Mann suggested that the orientation of calcite crystals growing underneath a monolayer might be dictated by a geometric and stereochemical complementarity between the (charged) headgroups of the monolayer and the ionic constituents of the nucleated crystal face. ${ }^{4}$ Their working hypothesis relates to a model of crystal nucleation sites in molluscan tissues, proposed some years earlier by Addadi and Weiner, who suggested that a self-organized array of acidic residues of immobilized aspartate rich proteins might serve as a template for formation of a uniformly oriented layer of aragonite crystal nuclei, the principal construction element of nacre ("mother-of-pearl"). ${ }^{5}$

This "template model of biomineralization" has stimulated a host of subsequent model studies, many of which provided further impetus on the notion of "molecular blueprinting" of inorganic materials by a pre-organized organic matrix. ${ }^{6}$ The unusual appeal of this model to many scientists might have sprung from the expectation that programming the epitaxial growth of inorganic materials by a directed design of monolayer-forming amphiphilic molecules should prove to be a straight-forward and simple task. However, comparative investigations on the growth of calcium carbonate underneath monolayers of structurally different amphiphilic compounds have brought this simple model into question. In contrast they have demonstrated that a geometric

Anorganische Chemie 2 (AC2), Materials and Catalysis, Universität Ulm, Albert-Einstein-Allee 11,D-89081,Ulm,Germany.E-mail: dirk.volkmer@ uni-ulm.de; Fax: (+49) 731/50-2 30 39; Tel: (+49) 731/50-2 3921 or stereochemical match between the monolayer and the incipient crystal layer is not a limiting condition for determining the spatial orientation or the formation of a particular polymorph of the inorganic material. ${ }^{7}$ While we do not rigorously want to rule out the existence of a heteroepitaxial relation between the organic template and the mineral in some special cases, the majority of experimental evidence is in favor of less delicate mechanisms such as a non-directional matching of surface charge density between the monolayer and the incipient crystal face. ${ }^{8}$ Moreover, there is growing experimental evidence for the fact that biogenic nacre is built up from a transient precursor phase of amorphous calcium carbonate, ${ }^{9}$ which spontaneously transforms into its wellknown brickwork crystal architecture, and this natural production strategy would be difficult to reconcile with an epitaxial growth mechanism.

The controversy of template mechanisms in biomineralization has led us to re-investigate a model system for biomineralization published by Heywood and Mann, who reported the selective nucleation of the calcite $\{00.1\}$ face underneath monolayers of $n$-eicosyl sulfate $\left(\mathrm{CH}_{3}\left(\mathrm{CH}_{2}\right)_{19} \mathrm{OSO}_{3}{ }^{-}\right)$and $n$-eicosyl phosphonate $\left(\mathrm{CH}_{3}\left(\mathrm{CH}_{2}\right)_{19} \mathrm{PO}_{3}{ }^{2-}\right){ }^{10}$ The selection of this particular crystal face was explained by an interfacial mechanism that involves stereochemical complementarity between the oxygen atoms of the $C_{3 \mathrm{v}}$-symmetric anionic headgroup and those carbonate ions located in lattice positions in the crystal faces of nuclei forming at the monolayer/solution interface (Scheme 1).

This model system represents a unique test case, since calcite crystals grown underneath monolayers of alkyl sulfates, sulfonates or phoshonates show a strictly uniform orientation, where the crystallographic $c$-axis of the calcite crystal lattice is oriented perpendicular to the monolayer. This is in contrast to many carboxylate terminated monolayers, which often show a predominant but no exclusive orientation of the nucleated calcite crystals (vide infra). ${ }^{6 a, b, d, 11}$ Moreover, the presence of sulfate-containing macromolecules in the calcitic prismatic as well as aragonitic nacreous layers of different mollusc shells supports the relevance of this study for biomineralization systems. ${ }^{12}$ 


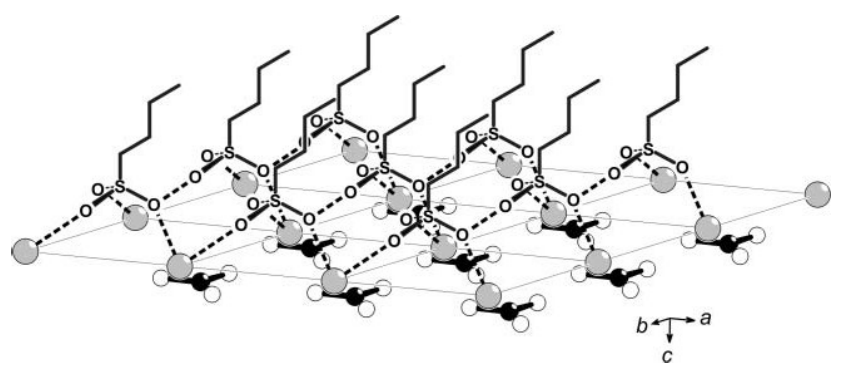

Scheme 1 Model of the interface between the monolayer of an anionic surfactant comprising of a $C_{3 \mathrm{v}}$-symmetric headgroup (here: an alkyl sulfonate), and the (00.1) plane of the calcite crystal lattice as suggested by Heywood and Mann. According to this, the selection of the (00.1) plane is dictated by a stereochemical and geometrical match between the charged headgroups and the underlying first layer of $\mathrm{Ca}$ ions. In the displayed $\mu_{3}$-bridging coordination mode, each sulfonate group replaces a $\mathrm{CO}_{3}{ }^{2-}$ anion at a crystallographically equivalent position. Note, however, that the proposed isostructural replacement of $\mathrm{CO}_{3}{ }^{2-}$ by $\mathrm{R}-\mathrm{SO}_{3}{ }^{-}$ions would lead to an unbalanced accumulation of charges at the interface, which constitutes an energetically unfavorable situation.

As can be seen in the interface model in Scheme 1, each sulfonate group might replace a $\mathrm{CO}_{3}{ }^{2-}$ anion in the $(00.1)$ plane of the calcite crystal lattice, assuming a $\mu_{3}$-bridging coordination mode for the sulfonate (or a similar $C_{3 \mathrm{v}}$-symmetric functional group). The persuasive nature of the simple model drawn in Scheme 1 has prompted us to investigate the crystal lattice and packing parameters of some $\mathrm{Ca}$ salts of the amphiphilic ligand octadecyl sulfonate. To our great surprise, we could not find as yet any experimental evidence for the formation of a coordination polymer in which the $\mathrm{Ca}$ ions are coordinated in the proposed fashion. Here, we present investigations on the synthesis and crystal structure of the compound $\left[\mathrm{Ca}\left(\mathrm{O}_{3} \mathrm{SC}_{18} \mathrm{H}_{37}\right)_{2}(\mathrm{DMSO})_{2}\right](\mathbf{1})$, and we discuss its packing parameters in light of the templating mechanism of its corresponding monolayer.

\section{Results and discussion}

\section{X-Ray crystallographic investigations}

Crystal structure of 1 . Single crystals of the compound $\left[\mathrm{Ca}\left(\mathrm{O}_{3} \mathrm{SC}_{18} \mathrm{H}_{37}\right)_{2}(\mathrm{DMSO})_{2}\right]\left(\mathrm{C}_{40} \mathrm{H}_{86} \mathrm{O}_{8} \mathrm{~S}_{4} \mathrm{Ca}, \mathbf{1}\right)$ were obtained by slow recrystallization of the crude product from DMSO- $\mathrm{H}_{2} \mathrm{O}$ mixtures $(10: 1)$ held at $98{ }^{\circ} \mathrm{C}$. Single crystals suitable for X-ray crystallographic investigations were hard to obtain, mainly due to the rapid loss of solvent molecules (within seconds) upon exposing the crystals to air. X-Ray crystallographic data for compound $\mathbf{1}$ are provided in Table 1.

The X-ray structure analysis of the compound [Ca$\left.\left(\mathrm{O}_{3} \mathrm{SC}_{18} \mathrm{H}_{37}\right)_{2}(\mathrm{DMSO})_{2}\right]$ (1) shows an interdigitated arrangement of the amphiphilic ligands (Fig. 1 and 2), in contrast to the more common bilayer structure motif of many membrane-forming lipids.

Each $\mathrm{Ca}$ ion is coordinated by four different sulfonate groups, and its nearly octahedral coordination environment is completed by two dimethyl sulfoxide (DMSO) ligands (Fig. 3).

The $\mathrm{Ca}$ ion lies on an inversion centre and there is one unique sulfonate ligand in the asymmetric unit which coordinates to the Ca ion via one of its three oxygen atoms. A second sulfonate oxygen at $(1+x, y, z)$ is also bonded to the calcium and the presence of the
Table 1 X-Ray crystallographic data for compound 1

\begin{tabular}{|c|c|}
\hline Compound & 1 \\
\hline Empirical formula & $\mathrm{C}_{40} \mathrm{H}_{86} \mathrm{O}_{8} \mathrm{~S}_{4} \mathrm{Ca}$ \\
\hline$M / \mathrm{g} \mathrm{mol}^{-1}$ & 863.41 \\
\hline Crystal system & Monoclinic \\
\hline Space group & $P 2_{1} / c$ (no. 14 ) \\
\hline$a / \AA$ & $5.4085(4)$ \\
\hline$b / \AA ̊$ & $8.1350(7)$ \\
\hline$c / \AA$ & $54.718(4)$ \\
\hline$\beta 1^{\circ}$ & $92.490(1)$ \\
\hline$V / \AA^{3}$ & $2405.2(3)$ \\
\hline$Z$ & 2 \\
\hline$D_{\mathrm{c}} / \mathrm{g} \mathrm{cm}^{-3}$ & 1.192 \\
\hline Crystal size/mm & $0.40 \times 0.20 \times 0.20$ \\
\hline Diffractometer type & SMART $1 \mathrm{~K}$ (Bruker AXS) \\
\hline$T / \mathrm{K}$ & $168(2) \mathrm{K}$ \\
\hline Radiation $(\lambda / \AA)$ & $\mathrm{Mo}-\mathrm{K} \alpha(0.71073)$ \\
\hline Scan type & $\varphi$ and $\omega$-scans \\
\hline $2 \theta$ Range for data collection $/^{\circ}$ & $4.48-54.06$ \\
\hline Index ranges, $h k l$ & -6 to $6,-5$ to $10,-69$ to 69 \\
\hline Reflections collected & 13005 \\
\hline Independent reflections $\left(R_{\text {int }}\right)$ & $5157(0.0380)$ \\
\hline Data/restraints/parameters & $5157 / 0 / 243$ \\
\hline Structure solution & SHELXS-97 \\
\hline Refinement program & SHELXL-97 \\
\hline Goodness-of-fit & 1.309 \\
\hline Final $R$ indices $[I>2 \sigma(I)]$ & $R_{1}=0.0997, w R_{2}=0.2274$ \\
\hline$R$ Indices (all data) & $R_{1}=0.1066, w R_{2}=0.2298$ \\
\hline Largest peak, hole/e $\AA^{-3}$ & $1.399,-0.869$ \\
\hline
\end{tabular}

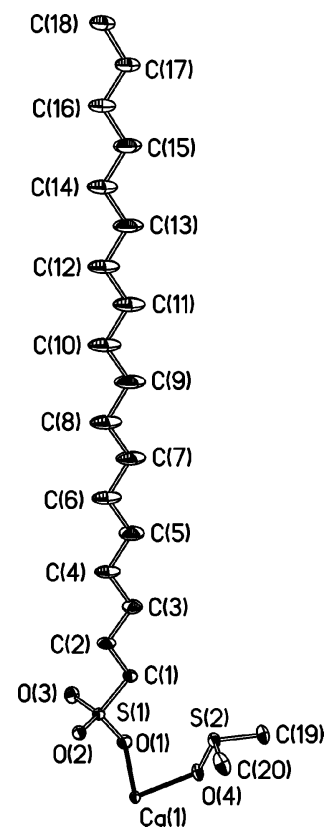

Fig. 1 Atomic numbering scheme for compound 1.

inversion centre ensures a necessarily planar (and almost square) $\mathrm{CaO}_{4}$ coordination; octahedral coordination at the calcium ion is then completed by a pair of inversion related DMSO ligands. The octadecyl sulfonate ligands coordinate to $\mathrm{Ca}$ in a $\eta^{1}, \mu_{2}$-mode, which contrasts to the $\mu_{3}$-bridging coordination mode suggested in the literature (Scheme 1) 


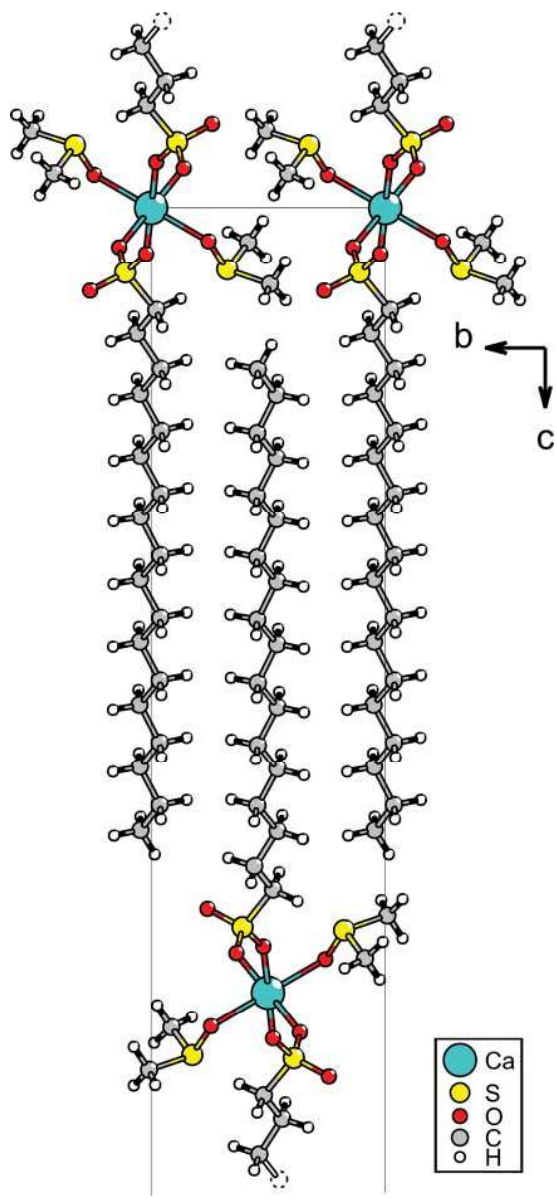

Fig. 2 Ball-and-stick model of the packing arrangement of $\mathbf{1}$ in its crystal lattice (octadecyl residues are partially cut off at the top and the bottom for clarity). The displayed area represents nearly half of the unit cell highlighting the interdigitated packing arrangement of hydrophobic residues. Unidimensional strands of the coordination polymer extend into the $a$-direction of the crystal lattice.

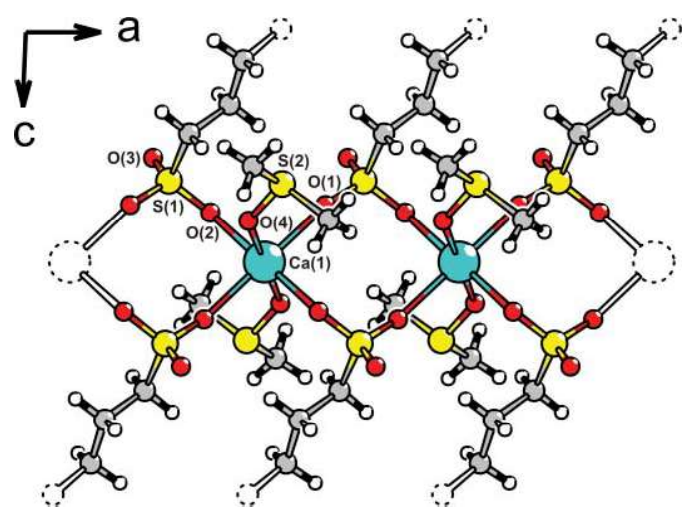

Fig. 3 Coordination scheme of 1 showing that the $\mu_{2}$-bridging coordination mode of octadecyl sulfonate ligands towards $\mathrm{Ca}$ ions (octadecyl residues were cut off for clarity). Each $\mathrm{Ca}$ ion is coordinated by four sulfonate groups stemming from different ligands, and their nearly octahedral coordination environment is completed by two monodentate DMSO ligands. Selected distances $(\AA)$ : $\mathrm{Ca}(1) \cdots \mathrm{Ca}(1) * 5.409(4), \mathrm{Ca}(1)-\mathrm{O}(1)$ 2.325(3), $\mathrm{Ca}(1)-\mathrm{O}(2)$ 2.325(4), $\mathrm{Ca}(1)-\mathrm{O}(4)$ 2.340(3), $\mathrm{S}(1)-\mathrm{O}(1)$ 1.465(4), $\mathrm{S}(1)-\mathrm{O}(2)$ 1.464(4), $\mathrm{S}(1)-\mathrm{O}(3)$ 1.441(4), $\mathrm{S}(2)-\mathrm{O}(4)$ 1.529(4).
The average surface area occupied by a single octadecyl sulfonate molecule in the $a b$-plane of the crystal structure of 1 amounts to $0.22 \mathrm{~nm}^{2}$. Since the alkyl chains are interdigitated, the density of sulfonate groups in the $a b$-plane is only half that value $\left(1 \mathrm{SO}_{3}^{-} / 0.44 \mathrm{~nm}^{2}\right)$ corresponding to an average surface charge density $\sigma$ of $2.27 \mathrm{SO}_{3}{ }^{-} / \mathrm{nm}^{2}$.

The calculated density of $\mathrm{SO}_{3}{ }^{-}$anions required for replacing $\mathrm{CO}_{3}{ }^{2-}$ ions in the (00.1) plane of the calcite lattice would be considerably higher: Assuming a close packing as suggested in the geometrical interface model in Scheme 1, a single $\mathrm{SO}_{3}{ }^{-}$anion would cover a surface area $A_{(00.1)}$ of $0.213 \mathrm{~nm}^{2}$ corresponding to an average surface charge density $\sigma$ of $4.69 \mathrm{SO}_{3}{ }^{-} / \mathrm{nm}^{2}$.

The calculated packing density (charge density, respectively) is considerably higher than the experimentally accessible packing densities in a close packed and compressed monolayer of $\mathbf{1}$ as determined from Langmuir isotherms of $\mathbf{1}$ spread on an aqueous subphase (see the following section).

A CSD database search on structurally related coordination compounds comprising of amphiphilic ligands with $C_{3 \mathrm{v}}$ symmetric headgroups showed that the available crystallographic data is very scarce. There has been so far, to the best of our knowledge, no report of a metal coordination polymer comprising amphiphilic non-branched alkyl sulfonate ligands such as in the structure of compound $\mathbf{1}$ presented here. For this reason we extended our database search on to similar amphiphilic compounds comprising a sulfate head group. There are in fact only a few structural reports on coordination compounds of the surfactant dodecyl sulfate. Representative packing diagrams of selected compounds are displayed in Fig. 4. These compounds have been chosen since they represent typical coordination motifs of the sulfate group in conjunction with different packing arrangements of the hydrophobic residues. Some noteworthy features of these compounds in the context of our investigations are as follows.

First, none of the compounds shown in Fig. 4 includes a coordination motif in which the sulfonate residues bind in a $\mu_{3}$ bridging coordination mode as suggested in Scheme 1. Note that the packing density increases from compounds (A) to (D) since as the content of coordinated water molecules in the crystal lattices diminishes. For the compound $\left[\mathrm{Mg}\left(\mathrm{H}_{2} \mathrm{O}\right)_{6}\right]\left(\mathrm{C}_{12} \mathrm{H}_{25} \mathrm{OSO}_{3}{ }^{-}\right)_{2}$ there are no coordinative bonds between metal ions and sulfate headgroups at all, whereas in compound $\left[\mathrm{Cu}^{\mathrm{II}}\left(-\mathrm{O}_{3} \mathrm{SOC}_{12} \mathrm{H}_{25}\right)_{2}\left(\mathrm{H}_{2} \mathrm{O}\right)_{4}\right]$, the dodecyl sulfate ligands are monodentately coordinated to the metal ions. In the compound $\left[\mathrm{Na}\left({ }^{-} \mathrm{O}_{3} \mathrm{SOC}_{12} \mathrm{H}_{25}\right)\left(\mathrm{H}_{2} \mathrm{O}\right)\right]$ each sulfate group is coordinated to five different metal ions, and in the compound $\left[\mathrm{Rb}\left(-\mathrm{O}_{3} \mathrm{SOC}_{12} \mathrm{H}_{25}\right)\right]$ there are two different coordination schemes, a $\mu_{2}-$ and a $\mu_{6}$-bridging coordination mode, respectively. (Note here that the metal ions of the latter compounds have only single charges). Summarizing the available crystallographic to date, we have to state that we, as yet, lack any structural examples of a coordination compound where the alkyl sulfate or sulfonate ligand binds to the metal ions in the scheme suggested in Scheme 1.

Second, the hydrophobic alkyl chains are either arranged in a typical bilayer structure motif or interdigitation of alkyl chains occurs. Note that the density of charged headgroups in a crystallographic plane parallel to the layer of alkyl chains is almost twice as high for the bilayer motif if compared to the interdigitated ("upside-down") arrangement of alkyl chains. Calculated crystal packing parameters of $\mathbf{1}$ and related compounds 


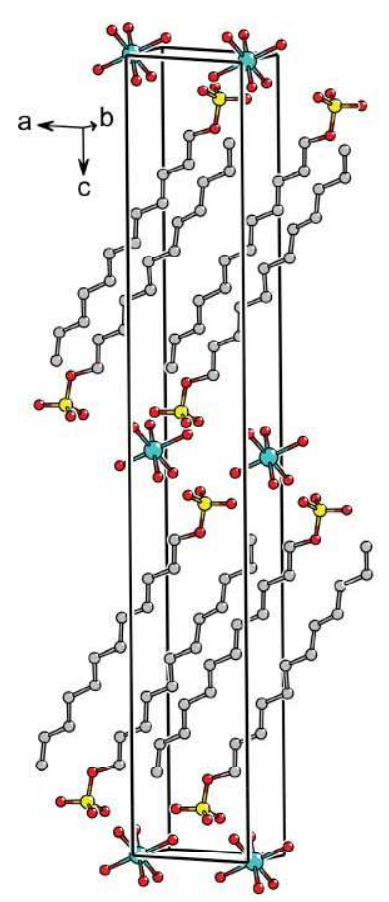

(A) TAKZEK

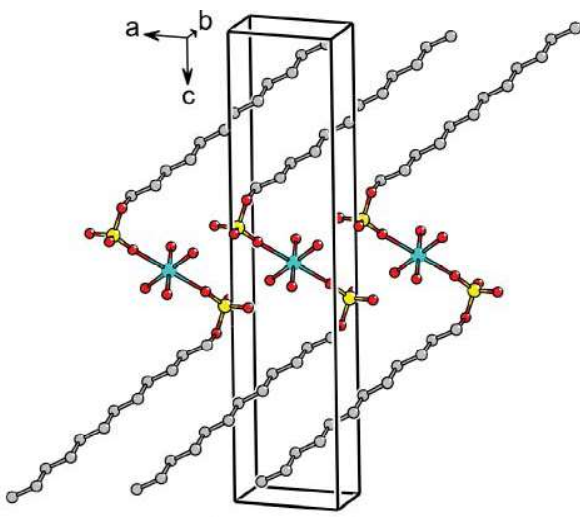

(B) ZEBRUT

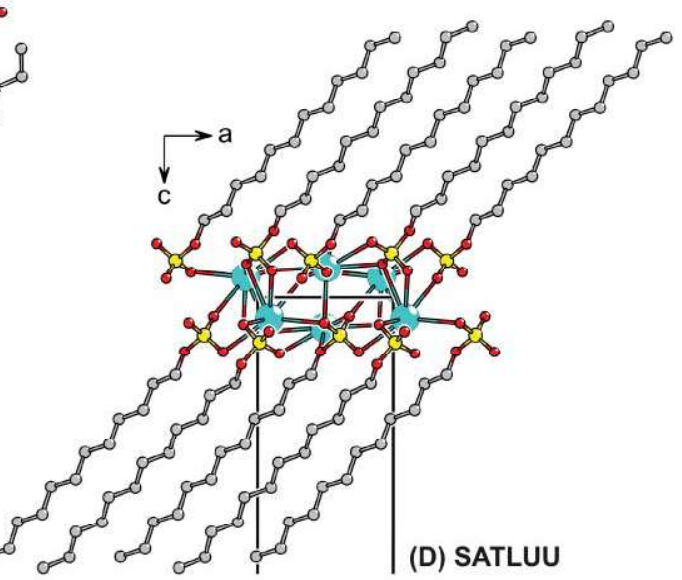

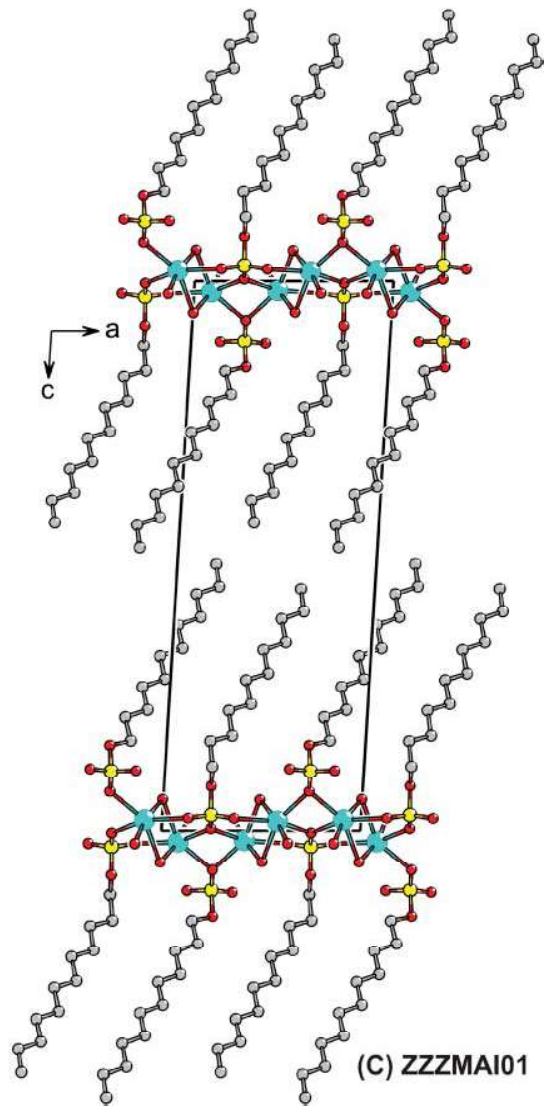

Fig. 4 Packing diagrams of selected coordination compounds comprising lamellar arrangements of dodecyl sulfate ligands (data taken from the CSD database, structure codes given in capital letters). Note that the packing density increases from (A) to (D) since the content of coordinated water molecules in the crystal lattices diminishes. Chemical data of compounds: (A) TAKZEK: $\left[\mathrm{Mg}\left(\mathrm{H}_{2} \mathrm{O}\right)_{6}\right]\left(\mathrm{C}_{12} \mathrm{H}_{25} \mathrm{OSO}_{3}^{-}\right)_{2},(\mathrm{~B}) \mathrm{ZEBRUT}\left[\mathrm{Cu}^{\mathrm{II}}\left({ }^{-} \mathrm{O}_{3} \mathrm{SOC}_{12} \mathrm{H}_{25}\right)_{2}\left(\mathrm{H}_{2} \mathrm{O}\right)_{4}\right]$, (C) ZZZMAI01: $\left[\mathrm{Na}\left({ }^{-} \mathrm{O}_{3} \mathrm{SOC}_{12} \mathrm{H}_{25}\right)\left(\mathrm{H}_{2} \mathrm{O}\right)\right]$, (D) SATLUU: [Rb $\left.\left(-\mathrm{O}_{3} \mathrm{SOC}_{12} \mathrm{H}_{25}\right)\right]$

are given in Table 2. These data indicate that the packing density of alkyl chains is maximized for those compounds showing an interdigitated arrangement, $\left(1\right.$, and $\left.\left[\mathrm{Mg}\left(\mathrm{H}_{2} \mathrm{O}\right)_{6}\right]\left(\mathrm{C}_{12} \mathrm{H}_{25} \mathrm{OSO}_{3}{ }^{-}\right)_{2}\right)$, where the average area per ligand in the $a b$-plane of the crystal lattice amounts to $\sim 0.22 \mathrm{~nm}^{2}$. For comparison, the average area values per ligand in those crystal structures showing a bilayer structure motif range from 0.266 to $0.35 \mathrm{~nm}^{2}$, and as a consequence, the alkyl chains are more tilted with respect to the monolayer plane.

\section{Monolayer studies}

Crystallographic investigations on the solid-state structure of $\mathbf{1}$ are complemented by monolayer studies. Monolayers were formed on aqueous subphases by spreading sodium octadecyl sulfonate from trichloromethane-methanol $(10: 1)$ solution using a Langmuir trough. Surface pressure-area $(\pi-A)$ isotherms provide information on monolayer stability and phase behavior. Fig. 5 shows the $\pi-\mathrm{A}$ isotherm of an octadecyl sulfonate monolayer

Table 2 Crystal packing parameters of 1 and structurally similar compounds

\begin{tabular}{lllllll}
\hline Compound & Chemical formula & Structure motif & $A_{\text {ab }} / \mathrm{nm}^{2}$ & $A_{\text {Ds }} / \mathrm{nm}^{2}$ & $\sigma / \mathrm{e}^{-} \mathrm{nm}^{-2}$ & Ref. \\
\hline $\mathbf{1}$ & {$\left[\mathrm{Ca}\left(\mathrm{O}_{3} \mathrm{SC}_{18} \mathrm{H}_{37}\right)_{2}(\mathrm{DMSO})_{2}\right]$} & Interdig. & 0.44 & 0.22 & 2.27 & This work \\
TAKZEK & {$\left[\mathrm{Mg}\left(\mathrm{H}_{2} \mathrm{O}\right)_{6}\right]\left(\mathrm{C}_{12} \mathrm{H}_{25} \mathrm{OSO}\right)_{2}$} & Interdig. & 0.44 & 0.22 & 2.27 & 19 \\
ZEBRUT & {$\left[\mathrm{Cu}\left(\mathrm{O}_{3} \mathrm{SOC}_{12} \mathrm{H}_{25}\right)_{2}\left(\mathrm{H}_{2} \mathrm{O}\right)_{4}\right]$} & Bilayer & 0.35 & 0.35 & 2.86 & 20 \\
ZZZMAI01 & {$\left[\mathrm{Na}\left(\mathrm{O}_{3} \mathrm{SOC}_{12} \mathrm{H}_{25}\right)\left(\mathrm{H}_{2} \mathrm{O}\right)\right]$} & Bilayer & 0.59 & 0.295 & 3.39 & 21 \\
SATLUU & {$\left[\mathrm{Rb}\left(\mathrm{O}_{3} \mathrm{SOC}_{12} \mathrm{H}_{25}\right)\right]$} & Bilayer & 0.53 & 0.266 & 3.76 & 22
\end{tabular}

Abbreviations used: $A_{\mathrm{ab}}=$ area of the $a b$-plane unit mesh; $A_{\mathrm{DS}}=$ av. area occupied by a dodecyl sulfate molecule in the $a b$-plane; $\sigma=$ av. surface charge density created by sulfate groups in the $a b$-plane 


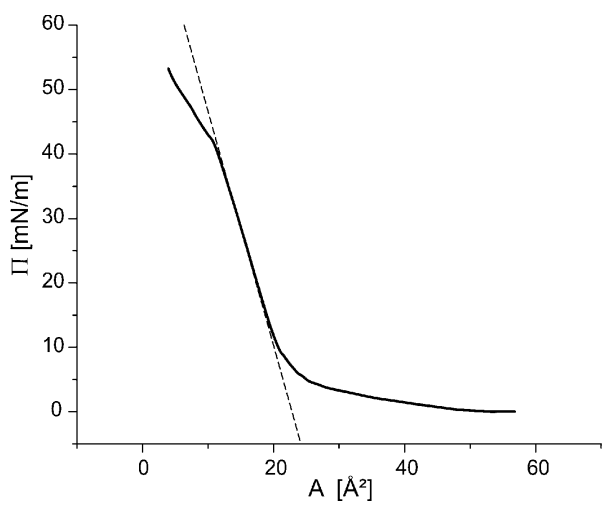

Fig. $5 \pi-A$ isotherm $\left(22^{\circ} \mathrm{C}\right)$ of octadecyl sulfonate spread on aqueous $\mathrm{CaCl}_{2} / \mathrm{NaHCO}_{3}(c=10 / 20 \mathrm{mM})$

spread on an aqueous subphase containing $\mathrm{CaCl}_{2} / \mathrm{NaHCO}_{3}(c=$ $10 / 20 \mathrm{mM}$ ). Since sodium octadecyl sulfonate is partially soluble in water, it was not possible to produce a stable monolayer on pure water. (A similar behavior has been reported for eicosyl sulfate. ${ }^{13}$ )

However, on a $10 \mathrm{mM}$ Ca-containing solution octadecyl sulfonate forms relatively stable monolayers, which upon compression start to collapse at a surface pressure above $40 \mathrm{mN}$ $\mathrm{m}^{-1}$ (Fig. 5). The featureless isotherm suggests that there is no sharp phase transition at $22{ }^{\circ} \mathrm{C}$. The first pressure increase is observed at an approximate area of $0.5 \mathrm{~nm}^{2}$ molecule ${ }^{-1}$. The average area per molecule of octadecyl sulfonate in the monolayer was estimated from extrapolating the Langmuir isotherms toward zero pressure. The value determined by averaging the isotherm data from Fig. 5 independent compression experiments amounts to $0.23 \mathrm{~nm}^{2}$ molecule ${ }^{-1}$ which is the same value as measured for monolayers of eicosyl sulfate spread on aqueous calcium sulfate solutions and in good agreement with the average area occupied by an octadecyl sulfonate molecule in the $a b$-plane of $\mathbf{1}$ $\left(=0.22 \mathrm{~nm}^{2}\right.$ molecule $\left.{ }^{-1}\right) .{ }^{14}$ Moreover this is close to the limiting area of non-branched amphiphilic alkanols, such as octadecanol. ${ }^{15}$ Note however, that the latter compounds have a sterically less bulky headgroup (-OH as opposed to $-\mathrm{SO}_{3}{ }^{-}$).

From the Langmuir isotherm shown in Fig. 5 we could thus deduce that the octadecyl sulfonate molecules might (at least partially) re-arrange from a disordered (liquid-like) arrangement into an interdigitated monolayer structure at high surface pressure. This assumption, however, would have to be justified by further experiments which are beyond the scope of the present investigation. However, crystal packing data (Table 2) calculated for the compounds shown in Fig. 4 indicate a simple correlation between the limiting area and the probable packing arrangement of the amphiphilic ligands. A direct comparison of the packing densities of these compounds indicates that only the interdigitated arrangement gives rise to a dense packing of alkyl chains approaching a limiting area of $0.22 \mathrm{~nm}^{2}$ molecule ${ }^{-1}$. For those compounds showing a bilayer arrangement of hydrophobic residues, the minimum limiting area is close to $0.27 \mathrm{~nm}^{2}$ molecule ${ }^{-1}$ for the compound of the maximum packing density (i.e. $\left[\mathrm{Rb}\left(\mathrm{O}_{3} \mathrm{SOC}_{12} \mathrm{H}_{25}\right)\right]$ ). This value is more than $20 \%$ higher than the calculated density of alkyl sulfonate moieties required for an isostructural replacement of $\mathrm{CO}_{3}{ }^{2-}$ ions in the (00.1) plane of the calcite lattice.

\section{$\mathrm{CaCO}_{3}$ crystallization underneath monolayers}

Since the original work of Heywood and Mann concentrated on the crystallization of calcite crystals underneath monolayers of n-eicosyl sulfate $\left(\mathrm{CH}_{3}\left(\mathrm{CH}_{2}\right)_{19} \mathrm{OSO}_{3}^{-}\right)$, we decided to repeat the experiments employing monolayers of octadecyl sulfonate and octadecyl sulfate, respectively. (In our monolayer investigations we are using a slightly different procedure to prepare the $\mathrm{Ca}\left(\mathrm{HCO}_{3}\right)_{2}$ solution, see the Experimental section.)

As can be seen in the micrographs shown in Fig. 6, the crystallization experiments in fact lead to formation of uniformly oriented calcite single crystals. The vast majority of crystals show the fundamental shape of a truncated rhombohedron. From the facts that the base of these pyramidal crystals constitutes an equilateral triangle, and the three visible, symmetry equivalent $\{10.4\}$ crystal faces show identical interfacial angles in the electron micrographs, we can directly conclude that the calcite crystals show a preferential growth orientation in which the $\{00.1\}$ is exposed to the monolayer. There are, however, pronounced differences in the regularity of crystal morphology. Whereas an octadecyl sulfonate monolayer leads to calcite crystals that frequently show an imperfect crystal shape (Fig. 6(a) and (b)), the calcite crystals grown underneath an octadecyl sulfate monolayers display perfectly smooth crystal faces (Fig. 6(c) and (d)). This unexpected behavior is highly reproducible under our experimental conditions and indicates that a much more complex calcite nucleation mechanism is occurring, as would be predicted by a "simple" epitaxy model, i.e. geometric matching between the charged monolayer and the incipient calcite crystal face.

At present we cannot offer a simple explanation for this marked difference in crystal growth behavior for the two different monolayers. For an ad hoc explanation we have to take into account that the Ca complexes of alkyl sulfonates and alkyl sulfates should have slightly different thermodynamic stabilities. However, in aqueous solution one would assume both $\mathrm{Ca}$ complexes to dissociate into the aquo complexes. Moreover, the kinetics of ligand exchange should be equally fast for both cases. Another aspect is the difference in chain length of the two amphiphiles which could lead to a pronounced "even-odd effect" on calcite crystals which grow underneath the monolayer. Such effects have been reported for the calcite growth on self-assembled monolayers of carboxylic acid terminated alkylthiols supported on gold. The oriented formation of two distinct crystallographic directions of calcite crystals with respect to the alkyl chain length was attributed to the different orientations of the functional group. ${ }^{16}$ Additionally, similar effects have been reported for the alteration of freezing point of ice crystals nucleated underneath monolayers of amphiphilic $n$-alkanols having different alkyl chain lengths. The difference in freezing point depression of the odd and even series of alcohols was attributed to different $2 \mathrm{D}$ packing arrangements which leads to different headgroup orientations at the monolayer/solution interface. ${ }^{17}$

Note, however, that the monolayers we have used to induce calcite crystal nucleation were held at low surface pressure $(\pi=$ $0.5 \mathrm{mN} \mathrm{m}^{-1}$ ) and it would thus be anticipated that the molecules could freely rearrange at the interface. ${ }^{18}$ 

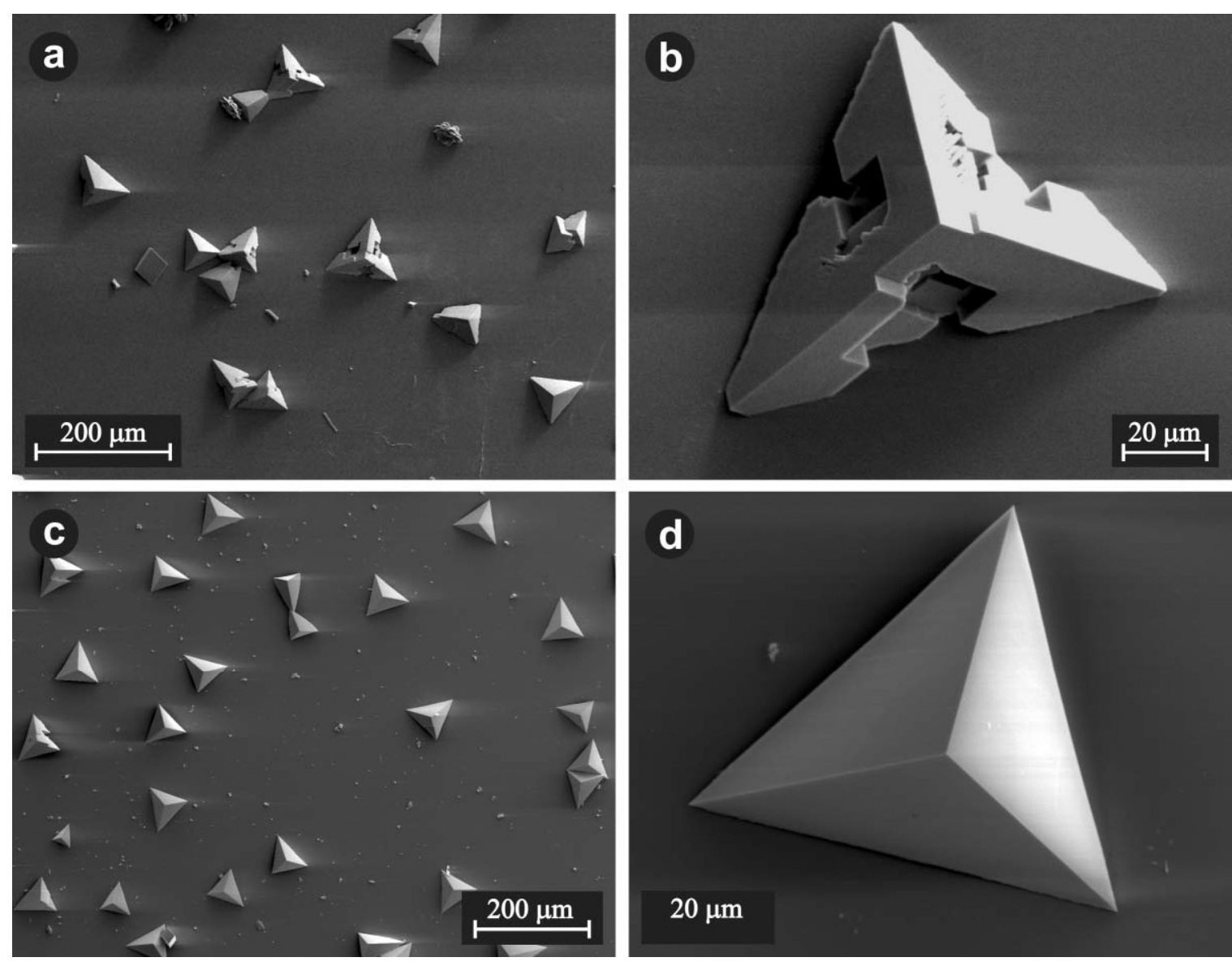

Fig. 6 Scanning electron micrographs of calcite single crystals occurring after $3 \mathrm{~h}$ underneath a slightly compressed monolayer of octadecyl sulfonate $(\mathrm{a}, \mathrm{b})$, underneath the monolayer of octadecyl sulfate (c, d). Experimental conditions: $\pi=0.1 \mathrm{mN} \mathrm{m}^{-1}, \mathrm{CaCl}_{2} / \mathrm{NaHCO}_{3} c=9 / 18 \mathrm{mM}$ ).

\section{Conclusions}

Summarizing the experimental data available from crystallographic data and compression isotherms we have thus to conclude that the interface model shown in Scheme 1 is physically unrealistic, since it would require the octadecyl surfactants to assemble into a monolayer structure with an exceptionally high packing density. This packing density can only be approached if the surfactant molecules assume an interdigitated packing arrangement. However, as a direct consequence of the interdigitated arrangement, the average charge density in the monolayer plane would be roughly half of that of a bilayer arrangement, and thus the mismatch of charges in the interface would get worse.

The available crystal structures of $n$-alkyl sulfonate or sulfate metal complexes provide no example of a coordination mode, in which the sulfonate or sulfate headgroup bridges three metal ions in a symmetrical fashion. The local $C_{3 \mathrm{v}}$-symmetry of the coordinating headgroups seems to be a necessary requirement for inducing the formation of calcite crystals which are truncated alongside their $\{00.1\}$ crystal faces. However, the selection of this crystal face is unlikely to be governed by a stereochemical match between the monolayer and the incipient crystal face. A clear-cut solution for this puzzling phenomenon clearly requires analytical methods that are capable of deriving an atomistic model of the monolayer/solution interface during the early time steps of crystal nucleation.

\section{Experimental}

Compounds sodium 1-octadecyl sulfonate (Fluka, p.a., $\geq 99.0 \%$ ) and sodium 1-octadecyl sulfate (Aldrich, technical grade, 93\%) were used without further purification.

\section{(1) Single crystals of Ca complex of 1}

The sodium salt of 1-octadecyl sulfonate $(71.5 \mathrm{mg}, 0.2 \mathrm{mmol})$ and calcium chloride $(14.7 \mathrm{mg}, 0.1 \mathrm{mmol})$ were suspended in $\mathrm{H}_{2} \mathrm{O}(10 \mathrm{~mL})$. The suspension was treated ultrasonically and centrifuged. The remaining pellet was suspended in $\mathrm{H}_{2} \mathrm{O}$ $(10 \mathrm{~mL})$, treated ultrasonically and centrifuged. The wet residue was dissolved in dimethyl sulfoxide $(6 \mathrm{~mL})$ and crystallized at $98^{\circ} \mathrm{C}$. Colorless crystals were obtained after 5 days.

\section{X-Ray structure analysis}

Details of structure refinement and X-ray crystallographic data are provided in the CIF file.

CCDC reference number 611718 . 
For crystallographic data in CIF or other electronic format see DOI: $10.1039 / \mathrm{b} 608760 \mathrm{~d}$

\section{Monolayer investigations}

Monolayer experiments were performed with a double-barrier NIMA trough using a compression speed of $15 \mathrm{~cm}^{2} \mathrm{~min}^{-1}$. The surface pressure of the monolayers was measured using a Wilhelmy plate. The surfactant was spread using a chloroform solution $\left(10 \mu 1,0.5 \mathrm{mg} \mathrm{mL}^{-1}\right)$. Compression was started after $10 \mathrm{~min}$.

\section{$\mathrm{CaCO}_{3}$ Crystal growth experiments}

Solutions of calcium bicarbonate were prepared by bubbling carbon dioxide gas through a stirred aqueous (Millipore water, resistance $18.2 \mathrm{M} \Omega \mathrm{cm})$ solution of $\mathrm{CaCl}_{2} / \mathrm{NaHCO}_{3}(c=9 / 18 \mathrm{mM})$ for a period of $2 \mathrm{~h}$. Compressed films were formed by adding known amounts of surfactant to generate a liquid- or solid-like film at the air-water interface. Crystals were studied at several time intervals either in situ by optical microscopy (Olympus IX 70) or on cover slips laid on the film. The cover slips were also mounted on scanning electron microscope (SEM) specimen tubs. Electron micrographs were taken from samples that were rotary shadowed with platinum $(3 \mathrm{~nm})$ in a Balzers BAF 300 freeze fracturing device and examined in a Hitachi S-5200 field emission scanning electron microscope.

Crystallographic indices of calcite crystals are presented in three-index $(h k l)$ notation, based on the hexagonal setting of the calcite unit cell $(R 3 c, a=4.96 \AA, c=17.002 \AA)$.

\section{Acknowledgements}

This work was financially supported by the Deutsche Forschungsgemeinschaft (DFG Schwerpunktprogramm 1117, "Prinzipien der Biomineralisation"; DFG grant Vo829/2-3).

\section{References}

1 (a) H. A. Lowenstam and S. Weiner, On Biomineralization, Oxford University Press, Oxford, 1989; (b) S. Mann, Biomineralization. Principles and Concepts in Bioinorganic Materials Chemistry, Oxford University Press, Oxford, 2001

2 S. Mann, Biomimetic Materials Chemistry, VCH, Weinheim, 1996.

3 (a) H. Cölfen and S. Mann, Angew. Chem., 2003, 115, 2452-2468; H. Cölfen and S. Mann, Angew. Chem., Int. Ed., 2003, 42, 2350-2365; (b) L. Addadi, D. Joester, F. Nudelman and S. Weiner, Chem. Eur. J., 2006, 12, 980-987.

4 B. R. Heywood and S. Mann, Adv. Mater., 1994, 6, 9-20

$5 \mathrm{~S}$. Weiner and L. Addadi, in Biomineralization, ed. S. Mann, VCH, Weinheim, 1989, pp. 133-156.

6 (a) A. Berman, D. J. Ahn, A. Lio, M. Salmeron, A. Reichert and D. Charych, Science, 1995, 269, 515-518; (b) S. Champ, J. A. Dickinson, P. S. Fallon, B. R. Heywood and M. Mascal, Angew. Chem., Int. Ed., 2000, 39, 2716-2719; (c) P. J. J. A. Buijnsters, J. J. J. M. Donners, S. J. Hill, B. R. Heywood, R. J. M. Nolte, B. Zwanenburg and N. A. J. M. Sommerdijk, Langmuir, 2001, 17, 3623-3628; (d) S. Cavalli, D. C. Popescu, E. E. Tellers, M. R. J. Vos, B. P. Pichon, M. Overhand, H. Rapaport, N. A. J. M. Sommerdijk and A. Kros, Angew. Chem., Int. Ed., 2005, 44, 1-7.

7 (a) D. Volkmer, M. Fricke, D. Vollhardt and S. Siegel, J. Chem Soc., Dalton Trans., 2002, 4547-4554; (b) D. Volkmer and M. Fricke, Z. Anorg. Allg. Chem., 2003, 629, 2381-2390; (c) M. Fricke and D. Volkmer, Top. Curr. Chem., 2006, DOI: 10.1007/128 063.

8 (a) D. Volkmer, M. Fricke, C. Agena and J. Mattay, J. Mater. Chem. 2004, 14, 2249-2259; (b) D. Volkmer, M. Fricke, M. Gleiche and L. Chi, Mater. Sci. Eng. C, 2005, 2, 161-167; (c) M. Fricke, D. Volkmer, C. E Krill, III, M. Kellermann and A. Hirsch, Cryst. Growth Des., 2006, 6, 1120-1123.

9 (a) I. M. Weiss, N. Tuross, L. Addadi and S. Weiner, J. Exp. Zool., 2002, 293, 478-491; (b) N. Nassif, N. Pinna, N. Gehrke, M. Antonietti, C. Jaeger and H. Cölfen, Proc. Natl. Acad. Sci. USA, 2005, 102, 1265312655.

10 B. R. Heywood and S. Mann, Chem. Mater, 1994, 6, 311-318

11 (a) S. Rajam, B. R. Heywood, J. B. A. Walker, S. Mann, R. J. Davey and J. D. Birchall, J. Chem. Soc., Faraday Trans., 1991, 87, 727-734; (b) D. Volkmer, M. Fricke, C. Agena and J. Mattay, CrystEng Comm, 2002, 4, 288-295; (c) E. Loste, E. Diaz-Marti, A. Zarbakhsh and F. Meldrum, Langmuir, 2003, 19, 2830-2837.

12 (a) Y. Dauphin, J.-P. Cuif, J. Doucet, M. Salome, J. Susini and C. T. Willams, J. Struct. Biol., 2003, 142, 272-280; (b) F. Nudelman, B. A Gotliv, L. Addadi and S. Weiner, J. Struct. Biol., 2006, 153, 176-187.

13 R. Wustneck, S. Siegel, T. Ebisch and R. Miller, J. Colloid Interface Sci., 1998, 203, 83-89.

14 T. Douglas and S. Mann, Mater. Sci. Eng. C, 1994, 193-199.

15 O. N. Oliveira, Jr. and C. Bonardi, Langmuir, 1997, 13, 5920-5924.

16 Y.-J. Han and J. Aizenberg, Angew. Chem., Int. Ed., 2003, 42, 36683670 .

17 J. Majewski, R. Popovitz-Biro, R. Edgar, M. Arbel-Haddad, K. Kjaer, W. Bouwman, J. Als-Nielsen, M. Lahav and L. Leiserowitz, J. Phys. Chem. B, 1997, 101, 8874-877.

18 D. J. Ahn, A. Berman and D. Charych, J. Phys. Chem., 1996, 100, 12455-12461.

19 V. M. Coiro and F. Mazza, Acta Crystallogr., Sect. C: Cryst. Struct. Commun., 1991, 47, 1169-1173.

20 C. S. Bruschini, M. G. B. Drew, M. J. Hudson and K. Lyssenko, Polyhedron, 1995, 14, 3099-3106.

21 V. M. Coiro, M. Manigrasso, F. Mazza and G. Pochetti, Acta Crystallogr., Sect. C: Cryst. Struct. Commun., 1987, 43, 850-854.

22 V. M. Coiro and F. Mazza, Acta Crystallogr., Sect. C: Cryst. Struct. Commun., 1989, 45, 1132-1136. 